\title{
Bacillus Calmette-Guérin-inoculation at different time points influences the outcome of C57BL/6 mice infected with Plasmodium chabaudi chabaudi AS
}

\author{
Dong-Hua Cao ${ }^{1,2}$, Ji-Chun Wang ${ }^{3}$, Jun Liu ${ }^{1}$, Yun-Ting Du ${ }^{1}$, Li-Wang Cui ${ }^{4}$ and Ya-Ming Cao ${ }^{1}$ \\ ${ }^{1}$ Department of Immunology, College of Basic Medical Sciences, China Medical University, Shenyang, China; \\ ${ }^{2}$ Aristogenesis Center, Hospital of People's Liberation Army, Shenyang, China; \\ ${ }^{3}$ Department of Microbiology and Parasitology, College of Basic Medical Sciences, China Medical University, Shenyang, China; \\ ${ }^{4}$ Department of Entomology, The Pennsylvania State University, University Park, Pennsylvania, USA
}

\begin{abstract}
Bacillus Calmette-Guérin (BCG) is an attenuated Mycobacterium tuberculosis vaccine. We performed a series of co-infection experiments with BCG-Plasmodium chabaudi chabaudi Landau, 1965 AS using C57BL/6 mice to analyse whether BCG can affect the development of protective immunity to infection with Plasmodium spp. and the mechanism of this protection. We divided mice into four groups: BCG-inoculation 4 weeks prior to P. c. chabaudi AS infection (B-4w-Pc); simultaneous BCG-inoculation and P. c. chabaudi AS infection (Pc+B); BCG-inoculation 3 days post P. c. chabaudi AS (Pc-3-B) infection; and mono-P. c. chabaudi AS infection as control $(\mathrm{Pc})$. The parasitemia level in the B-4w-Pc group was noticeably higher than control group at 6-19 days post infection (dpi). Compared with the control group, the proportion of $\mathrm{CD} 4{ }^{+} \mathrm{CD} 69^{+} \mathrm{T}$ cells was significantly reduced 5,8 and $12 \mathrm{dpi}$, but the proportion of $\mathrm{CD}^{+} \mathrm{CD} 25^{+} \mathrm{Foxp}^{+}$Tregs was significantly increased in the B-4w-Pc group on 5 and 8 dpi. The B-4w-Pc group also demonstrated reduced levels of IFN- $\gamma$ and TNF- $\alpha$ on 5 and 8 dpi and significantly elevated level of IL-10 on 12 dpi. There were significantly fewer mDCs $\left(\mathrm{CD} 11 \mathrm{c}^{+} \mathrm{CD} 11 \mathrm{~b}^{+}\right)$and $\mathrm{pDCs}\left(\mathrm{CD} 11 \mathrm{c}^{+} \mathrm{B} 220^{+}\right)$in the B-4w-Pc group than the control group at all the time points post infection and the expression of MHC II was noticeably reduced on day 8 pi. Our findings confirmed that BCG inoculation prior to Plasmodium infection resulted in excessive activation and proliferation of Tregs and upregulation of anti-inflammatory mediators, which inhibited establishment of a Th1-dominant immune response during the early stages of Plasmodium infection by inhibiting dendritive cells response. BCG inoculation prior to P. c. chabaudi AS infection may contribute to overgrowth of parasites as well as mortality in mice.
\end{abstract}

Keywords: murine malarial parasite, $\mathrm{BCG}$, co-infection, protective immunity

Malaria and tuberculosis are major causes of morbidity and mortality worldwide. According to the latest estimates from the World Health Organization (WHO), there were about 214 million cases of malaria and an estimated 438000 deaths in 2015 (World Health Organization 2015). Equally serious is the global burden of tuberculosis. In 2013, an estimated 9 million people developed tuberculosis and 1.5 million died from the disease (World Health Organization 2014). Given the substantial overlap of geographic distribution between endemic regions for these two diseases and especially the large number of individuals with latent tuberculosis living in malaria-endemic regions, co-infection with malaria and tuberculosis is likely to be common (Range et al. 2007, Thapa et al. 2010).

The clinical manifestations of malaria may vary from asymptomatic infection to life-threatening anemia to neurologic involvement. Although adaptive immunity plays a significant role in the development and outcome of disease, other factors from the host and environment likely contribute to the variability in clinical manifestation (Artavanis-Tsakonas et al. 2003). In malaria-tuberculosis co-endemic areas, many children at risk for severe malaria have experienced mycobacterial infections from either exposure to Mycobacterium tuberculosis, environmental mycobacteria, or routine vaccination with Bacillus Calmette-Guérin (BCG). However, the modulatory mechanism by which the host immune responses to parasites of Plasmodium Marchiafava et Celli, 1885 are modulated by concurrent infections from $M$. tuberculosis or BCG remains poorly understood.

Infection with Plasmodium chabaudi chabaudi Landau, 1965 of mice is a model of human malaria. This rodent malaria has many features in common with human disease (Cox et al. 1987, Gilks et al. 1990, Mackinnon et al. 2002)

Address for correspondence: Y.-M. Cao, Department of Immunology, College of Basic Medical Sciences, China Medical University, No. 77 Puhe Road, Shenbei New District, Shenyang 110112, China. Phone: 0086-18900911233; E-mail: ymcao@mail.cmu.edu.cn 
and has been used extensively in laboratory research on malaria (Barclay et al. 2012, Schneider et al. 2012, Spence et al. 2012, Cameron et al. 2013, Waisberg et al. 2013). Infection with $P$. c. chabaudi AS is typically self-resolving in C57BL/6 mice; however, it is lethal in A/J mice (Langhorne et al. 2002). The mechanisms for this phenomenon have been extensively investigated (Langhorne et al. 1989, Stevenson et al. 1990, 1995, Stevenson and Tam 1993, Sam and Stevenson 1999) and it is widely accepted that the different outcomes are due to balance and timing of the Th1 and Th2 immune responses (Taylor-Robinson et al. 1993). Our recent data showed that BALB/c mice initiated a Th1/Th2 profile response to $P$. c. chabaudi AS infection, yet DBA/2 mice failed to control the same infection and almost all of them died post-peak parasitemia. Furthermore, we found a higher proportion of Treg cells with elevated Foxp3 expression in $\mathrm{DBA} / 2$ than in $\mathrm{BAL}$ $\mathrm{B} / \mathrm{c}$ mice, suggesting that the disparity of immune response to $P$. c . chabaudi AS between $\mathrm{BALB} / \mathrm{c}$ and $\mathrm{DBA} / 2$ mice may be associated with suppressive activities of Treg cells (Wang et al. 2013).

Earlier studies have reported that vaccination with BCG protects mice against Plasmodium vinckei Rhodain, 1952, P. yoelii Landau et Killick-Kendrick, 1966, P. berghei Vincke et Lips, 1948, and P. c. chabaudi (Clark et al. 1976, Murphy 1981, Stevenson et al. 1984). The protective factor could be found in the serum of mice pre-infected with BCG and was toxic to both murine and human malarial parasites (Clark et al. 1981, Taverne et al. 1981, 1982, Haidaris et al. 1983, Wozencraft et al. 1984). A later study investigating the mechanism by which BCG can protect hosts against malaria demonstrated that BCG-vaccination could dramatically increase the survival rates of suscep $\neg$ tible A/J mice from infection by $P$. yoelii $17 \mathrm{XL}$. Analysis of splenocytes indicated that BCG vaccination biased the immune response toward a Th1 type response (Matsumoto et al. 2000). However, the immunological mechanisms underlying these phenomena have not been well delineated.

With this in mind, in the present study we performed a series of co-infection experiments with BCG-P. c. chabaudi AS using C57BL/6 mice in order to elucidate which co-infection phase/phases (BCG-inoculation pre-P. c. chabaudi AS infection, simultaneous BCG-inoculation with P. c. chabaudi AS infection, and/or BCG-inoculation post- $P$. c. chabaudi AS) can affect the development of protective immunity to $P$. c c chabaudi AS infection. We focused our study on the mechanism of this protection.

\section{MATERIALS AND METHODS}

Mice, parasites, experimental infection and BCG-inoculation

Female C57BL/6 mice, aged 6-8 weeks, were purchased from the Shanghai Branch of the Chinese Academy of Sciences, Centre of Zoology. The Plasmodium c. chabaudi AS strain was kindly provided by Motomi Torii (Department of Molecular Parasitology, Ehime University Graduate School of Medicine, Ehime, Japan). Infections were initiated via intraperitoneal (i.p.) injec- tion of $1 \times 10^{6}$ P. c. chabaudi AS-parasitised erythrocytes into C57BL/ 6 mice. For BCG inoculation, 0.25-mg freeze-dried BCG vaccine vials (Shanghai Institute of Biological Products, China National Biotec Group, Shanghai, China; Lot 2009030901) were reconstituted in $500 \mu \mathrm{l}$ sterile saline. The required infective dose per mouse was $5 \times 10^{4}$ of BCG, delivered in a volume of $100 \mu 1$ via intravenous injection into the tail vein. Mice were divided into 4 groups by time of inoculation: mice inoculated with BCG 4 weeks pre-P. c. chabaudi AS infection (B-4w-Pc); mice inoculated with BCG and simultaneously infected with $P$. c. chabaudi AS $(\mathrm{Pc}+\mathrm{B})$; mice inoculated with $\mathrm{BCG} 3$ days post-P. c. chabaudi AS infection (Pc-3-B); and mice infected with mono-P. c. chabaudi AS as control $(\mathrm{Pc})$. No mice died as a result of the BCG inoculation. For the parasitemia and survival experiment, 10 mice were used in each group. Parasitemia was monitored at each time point by microscopic examination of Giemsa-stained thin tail blood smears and mortality was monitored daily. For the immunological study, five mice were used per group and each experiment was repeated three times. All experiments were performed in compliance with local animal ethics committee requirements.

\section{Splenocyte culture and quantification of cytokines}

Splenocytes were harvested and cultured essentially as previously described (Chen et al. 2009). Aliquots $\left(5 \times 10^{6} /\right.$ well) of the cell suspensions were seeded in 24-well flat-bottom tissue culture plates (Falcon) in triplicate for $48 \mathrm{~h}$ at $37^{\circ} \mathrm{C}$ in a humidified $5 \%$ $\mathrm{CO}_{2}$ incubator. Supernatant fractions were collected and stored at $-80^{\circ} \mathrm{C}$ until they were assayed. Levels of IFN- $\gamma$, TNF- $\alpha$ and IL10 in culture supernatants were measured using enzyme linked immunosorbent assays (ELISA) (R\&D Systems, Minneapolis, MN, USA).

\section{Flow cytometry analysis}

Splenocytes from a portion of each group were collected to determine the relative percentage of Th1 type cells $\left(\mathrm{CD} 4^{+} \mathrm{CD} 69^{+}\right)$, Tregs $\left(\mathrm{CD}^{+} \mathrm{CD} 25^{+} \mathrm{Foxp}^{+}\right)$, the subsets of splenic myeloid DCs $\left(\mathrm{mDC}, \mathrm{CD} 11 \mathrm{c}^{+} \mathrm{CD} 11 \mathrm{~b}^{+}\right)$and plasmacytoid DCs (pDC, CD$\left.11 \mathrm{c}^{+} \mathrm{B} 220^{+}\right)$, and the expression of MHC II on DCs (CD11 $\mathrm{c}^{+} \mathrm{MHC}$ $\left.\mathrm{II}^{+}\right)$. Unless otherwise indicated, antibodies were purchased from BD Biosciences. When mouse cells were analysed, the following antibodies were used: FITC-conjugated anti-CD11c (clone HL-3), PE-conjugated anti-CD11b (clone M1/70), PerCP-conjugated anti-B220 (clone RA3-6B2), PE-conjugated anti-MHC II (clone M5/114.15.2, eBioscience), FITC-conjugated anti-CD69 (clone H1.2F3), FITC-conjugated anti-CD4 (clone GK1.5), PE-conjugated anti-CD25 (clone PC61), and APC-conjugated anti-Foxp3 (clone FJK16s, eBioscience). Flow cytometry was performed on a FACS Calibur (BD Biosciences, San Diego, CA, USA) and analysed using the FlowJo software (Treestar, San Carlos, CA, USA).

\section{Statistical analysis}

Data are presented as the mean \pm standard error of the mean (SEM). Survival analysis was performed using the Kaplan-Meier log-rank test. Statistical significance of the differences was analysed by the $t$-test or one way ANOVA (SPSS 17.0). A value of $P<0.05$ was considered significant. 
A

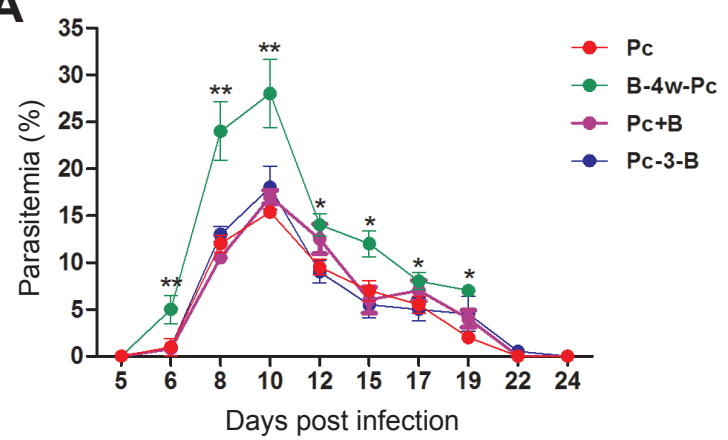

B

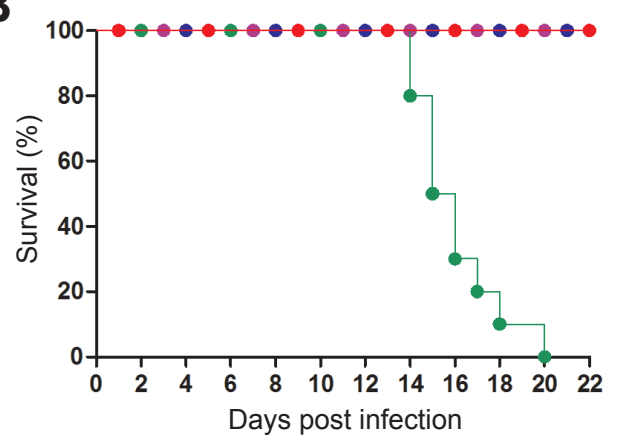

Fig. 1. The effect of BCG-inoculation on the level of parasitemia and survival rate of C57BL/6 mice during infection with Plasmodium chabaudi chabaudi Landau, 1965 AS. Parasitemia (A) and survival rate (B) in C57BL/6 mice after BCG-innoculation 4 weeks prior to infection with P. c. chabaudi AS (B-4w-Pc), simultaneous BCG-innoculation and infection with $P$. c. chabaudi AS (Pc+B), BCG-innoculation 3 days post-infection with P. c. chabaudi AS (Pc-3-B), and monoinfection with P. c. chabaudi AS as control (Pc). A Giemsa-stained thin smear was analysed daily in order to monitor for the presence of parasitemia. Values represent the mean $\pm \mathrm{SEM}$ (n $=10$ mice per group). * indicates $P<0.05$ and ** indicates $P<0.01$ between the B-4w-Pc and Pc groups.

A
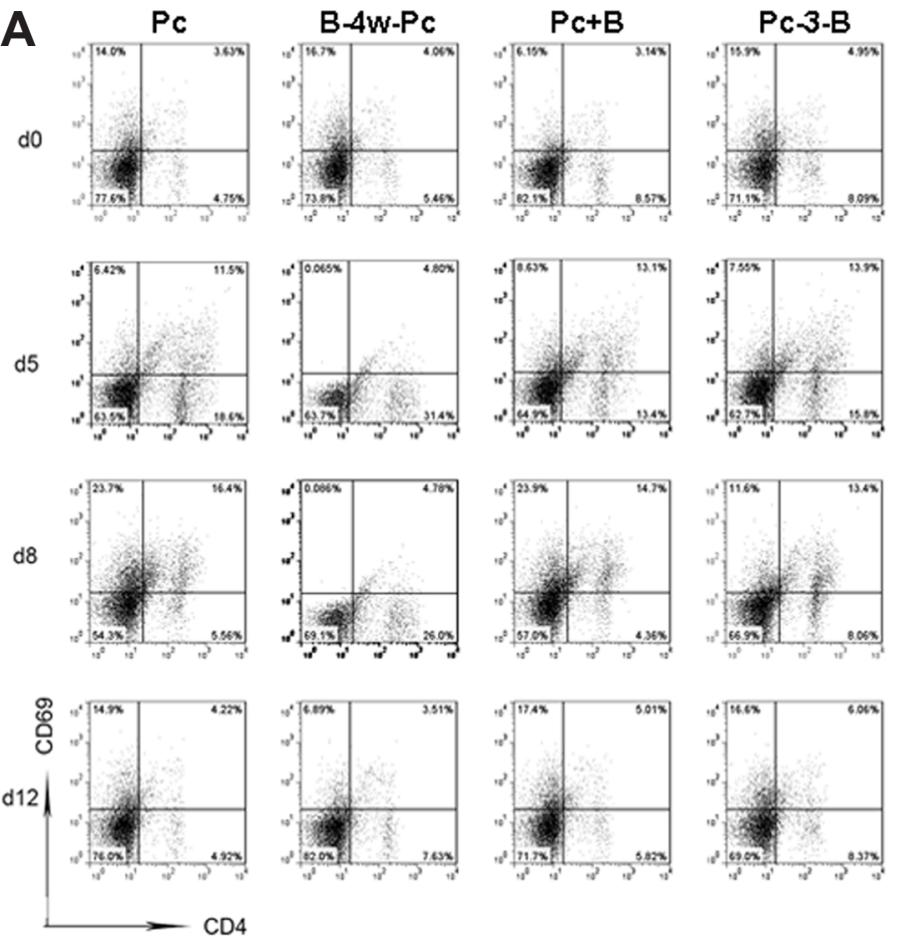

B
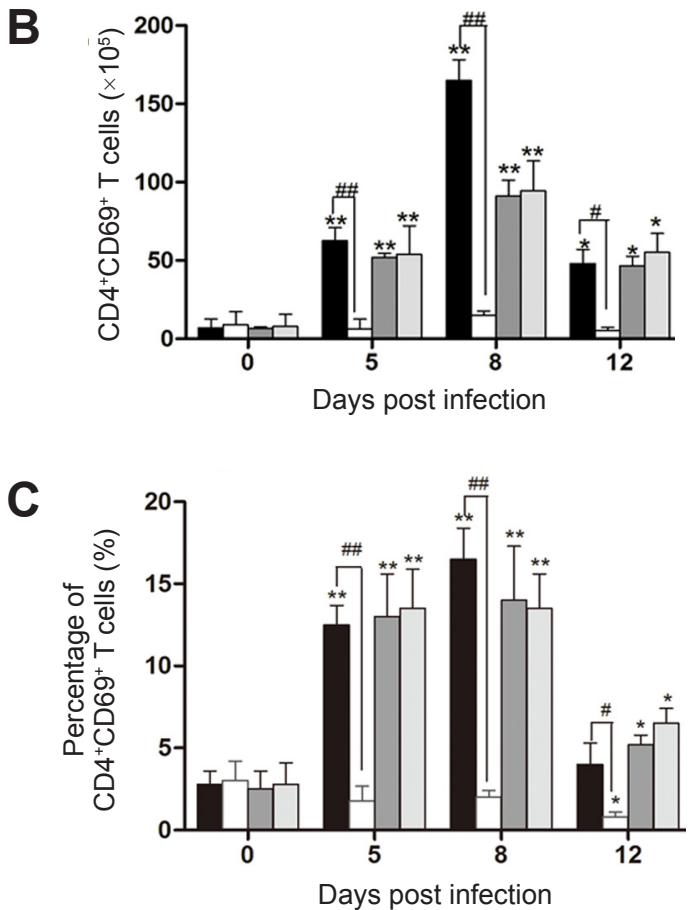

D

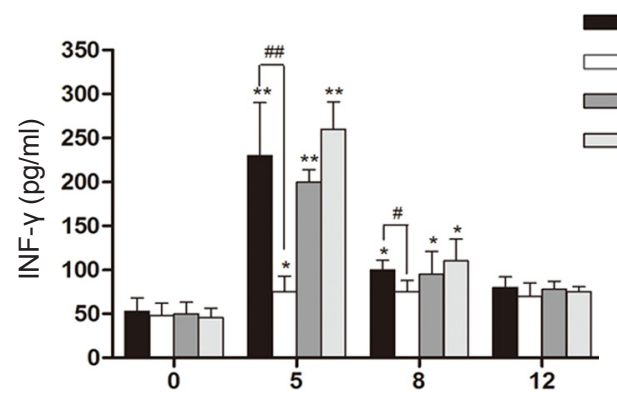

Days post infection
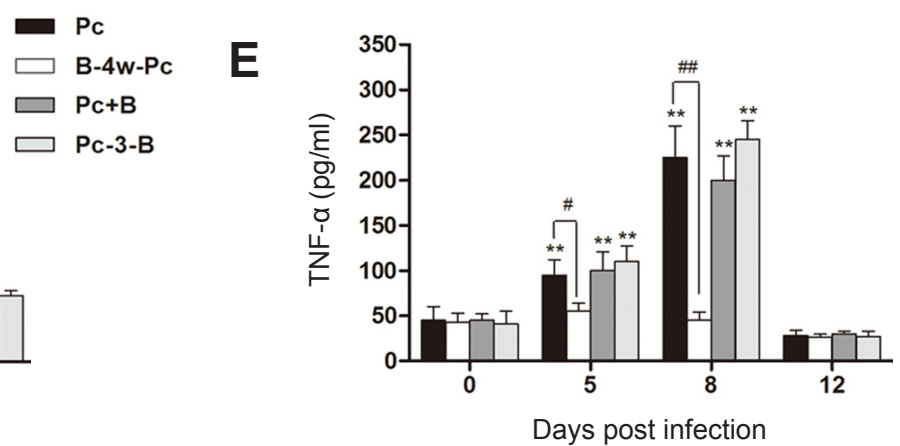

Fig. 2. The effect of BCG-inoculation on the pro-inflammatory immune responses of C57BL/6 mice during infection with Plasmodium chabaudi chabaudi Landau, 1965 AS. On day 0 (non-infection), 5, 8 and 12 days post infection, the proportion of $\mathrm{CD} 4{ }^{+} \mathrm{CD} 69^{+} \mathrm{T}$ cells was detected using flow cytometry. Illustration of the gating strategy for identifying splenic $\mathrm{CD} 4{ }^{+} \mathrm{CD} 69^{+} \mathrm{T}$ cells using representative dot plots (A). Absolute number and proportion of $\mathrm{CD} 4{ }^{+} \mathrm{CD} 69^{+} \mathrm{T}$ cells at various time points post infection $(\mathbf{B}$ and $\mathbf{C})$. Splenic lysates were prepared and the concentrations of IFN- $\gamma(\mathbf{D})$ and TNF- $\alpha(\mathbf{E})$ were determined by ELISA. Each experiment was repeated three times. Values represent the mean \pm SEM ( $\mathrm{n}=5$ mice per group). * indicates $P<0.05$ and $* *$ indicates $P<0.01$ between experimental groups and non-infected mice; \# indicates $P<0.05$ and \#\# indicates $P<0.01$ between BCG-innoculated mice and control. 
A
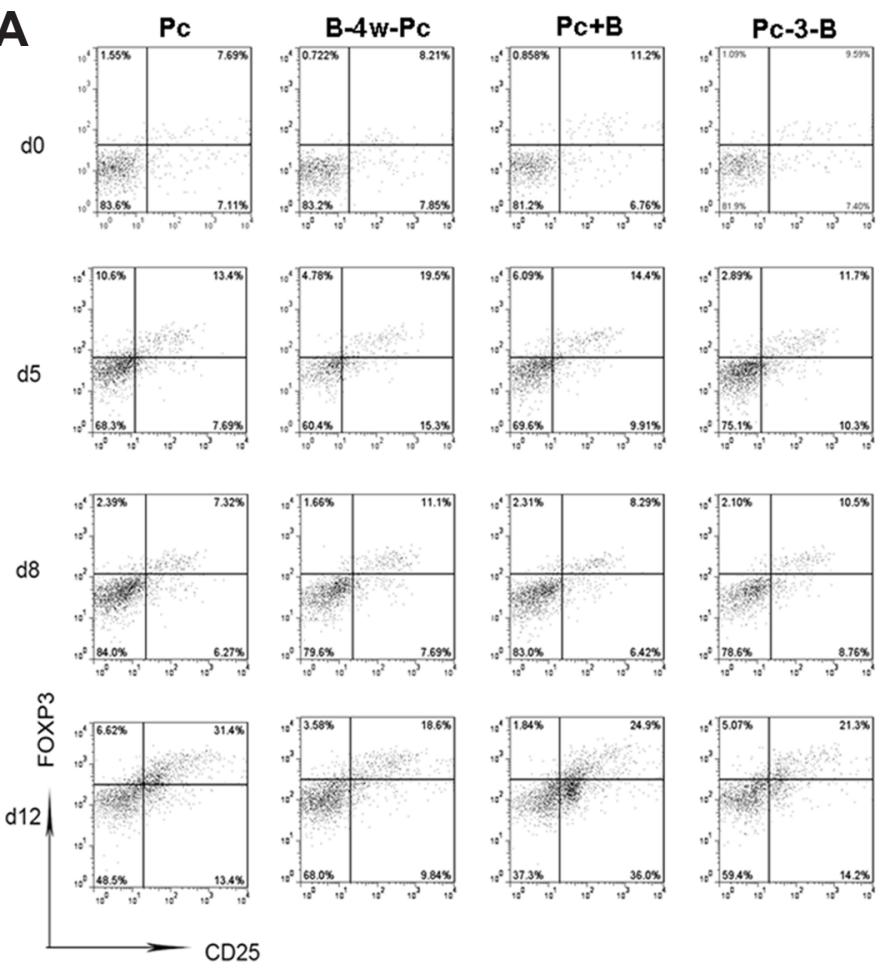

CD25
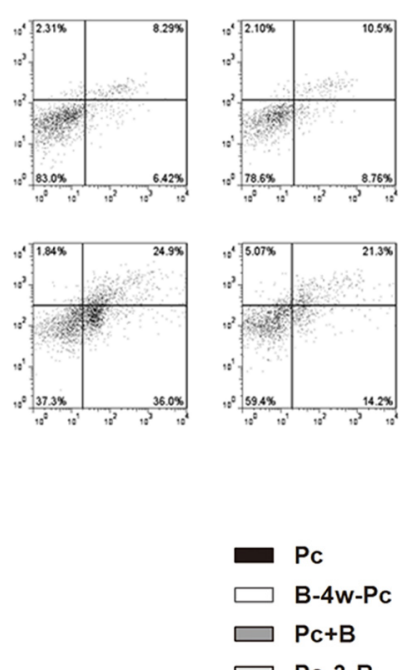

B

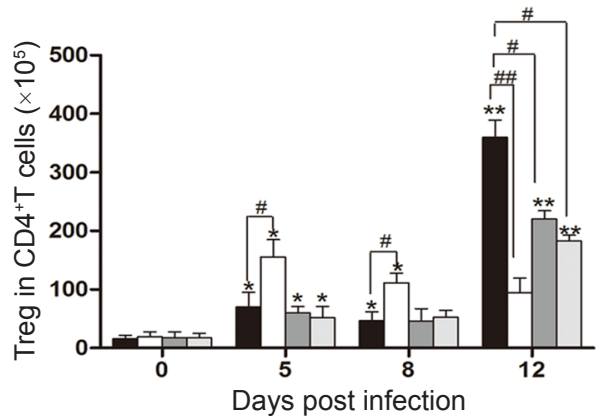

C

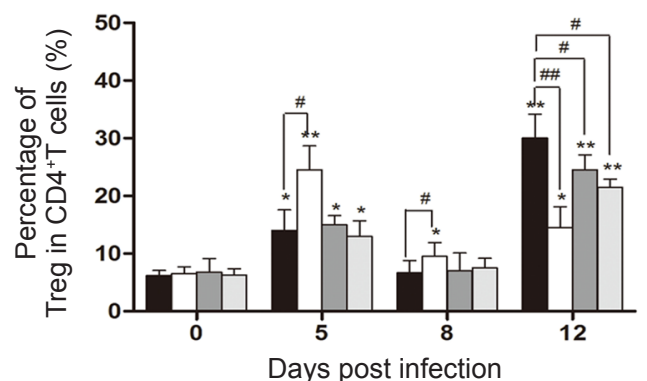

D

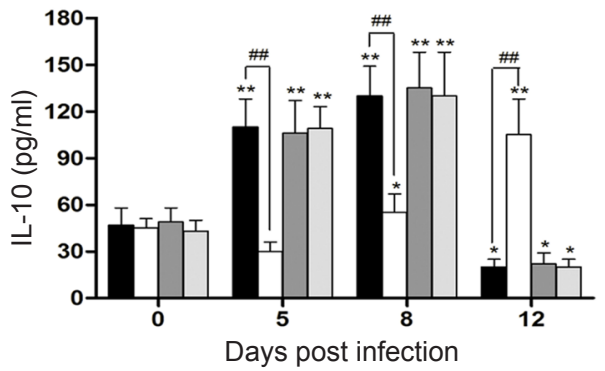

Fig. 3. The effect of BCG-inoculation on Tregs and anti-inflammatory cytokine production in C57BL/6 mice during infection withPlasmodium chabaudi chabaudi Landau, 1965 AS. On 0 (non-infection), 5, 8 and 12 days post infection, the proportion of CD4 $4^{+} \mathrm{CD} 25^{+-}$ Foxp $3^{+} \mathrm{T}$ cells was quantified using flow cytometry. Illustration of the gating strategy for identifying splenic $\mathrm{CD} 4^{+} \mathrm{CD} 25^{+} \mathrm{Foxp} 3^{+} \mathrm{T}$ cells using representative dot plots (A). Absolute number and proportion of $\mathrm{CD} 4{ }^{+} \mathrm{CD} 25^{+} \mathrm{Foxp} 3^{+} \mathrm{T}$ at various time points post infection $(\mathbf{B}$ and C). Splenic cell culture suspensions were collected and the level of IL-10 protein was measured by ELISA (D). Each experiment was repeated three times. Values represent the mean \pm SEM $(\mathrm{n}=5$ mice per group $){ }^{*}$ indicates $P<0.05$ and ** indicates $P<0.01$ between experimental groups and non-infected mice; \# indicates $P<0.05$ and \#\# indicates $P<0.01$ between BCG-innoculated mice and control.

\section{RESULTS}

The effect of BCG-inoculation on parasitemia and the survival rate of $\mathrm{C57 \textrm {BL } / 6}$ mice during infection with Plasmodium chabaudi chabaudi AS

To determine whether pre-, post- or concurrent BCG-inoculation affected the survival rate of C57BL/6 mice during infection with Plasmodium c. chabaudi AS, parasitemia was monitored at each time point and mortality was monitored daily. The level of parasitemia in the Pc group (control) began to rise on 5 day post infection (dpi), then increased rapidly from $1 \%$ to $12 \%$ during days $6-8$ dpi and reached a mean peak level of $15.4 \%$ on days 9, 10 dpi. From that, the parasitemia began to decrease and all mice recovered by 22 dpi. The level of parasitemia in the B-4w-Pc group was noticeably higher than the control group on 6-19 dpi $(P<0.01$ on 6,8 and $10 \mathrm{dpi} ; P<0.05$ on $12,15,17$ and 19 dpi) (Fig. 1A). All mice succumbed to P. c. chabaudi AS infection by 20 dpi (Fig. 1B). The susceptibility to infection of the $\mathrm{Pc}+\mathrm{B}$ and $\mathrm{Pc}-3-\mathrm{B}$ groups was similar to that of the control group (Fig. 1A,B). These results suggest that it was only the group with an established BCG pre-infection that had a different outcome from the other 3 groups.

The effect of BCG-inoculation on the pro-inflammatory immune responses of $\mathrm{C} 57 \mathrm{BL} / 6$ mice during infection with Plasmodium chabaudi chabaudi AS

To elucidate whether BCG-inoculation could regulate the pro-inflammatory immune response, which in turn could affect the outcomes of BCG-malaria co-infection, we detected the kinetics of the $\mathrm{CD} 4^{+} \mathrm{CD} 69^{+} \mathrm{T}$ cell response and the concentrations of IFN- $\gamma$ and TNF- $\alpha$ in different mouse models. The absolute number and proportion of $\mathrm{CD}^{+} \mathrm{CD} 9^{+} \mathrm{T}$ cells in the $\mathrm{Pc}+\mathrm{B}$ and $\mathrm{Pc}-3-\mathrm{B}$ groups significantly increased on days 5 pi and 8 pi $(P<0.01)$. However, there was a remarkable reduction in the percentage of CD $4^{+} \mathrm{CD} 69^{+} \mathrm{T}$ cells on 5, $8(P<0.01)$ and $12 \mathrm{dpi}(P<0.05)$ in the B-4w-Pc group as compared to control (Fig. 2B,C). Consistent with these changes in the $\mathrm{CD} 4^{+} \mathrm{CD} 69^{+} \mathrm{T}$ cell population, similar results in the levels of IFN- $\gamma$ and TNF- $\alpha$ from splenocyte culture supernatants were observed in each groups (Fig. 2D,E). 
A
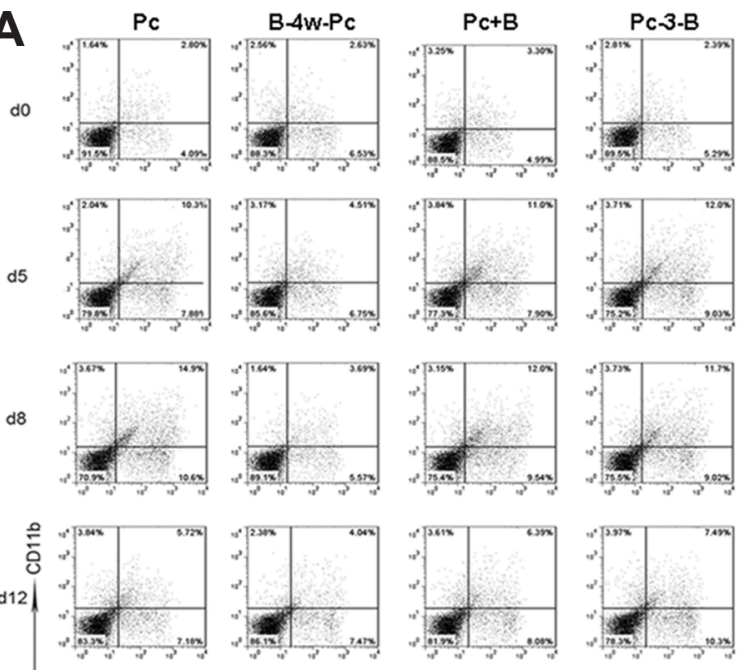

D
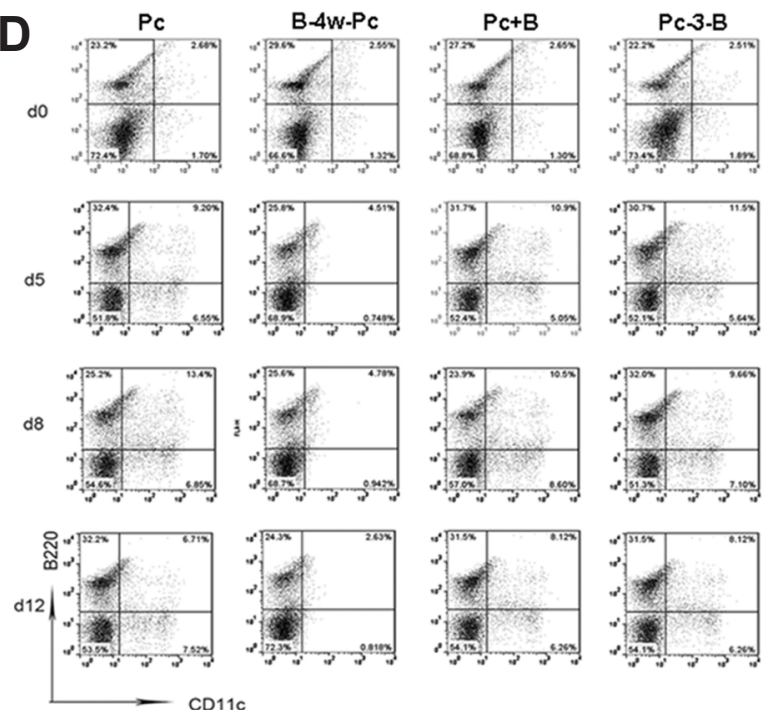

G
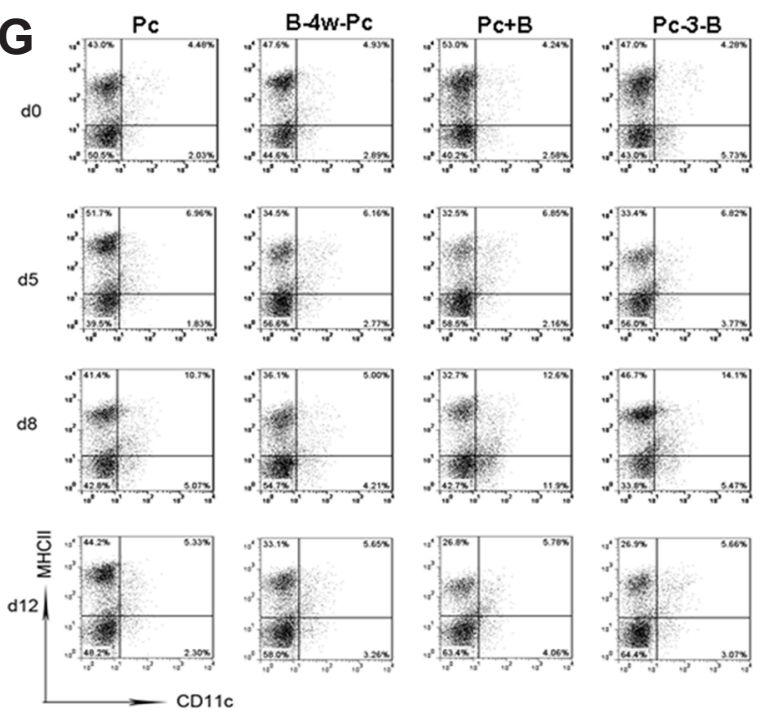
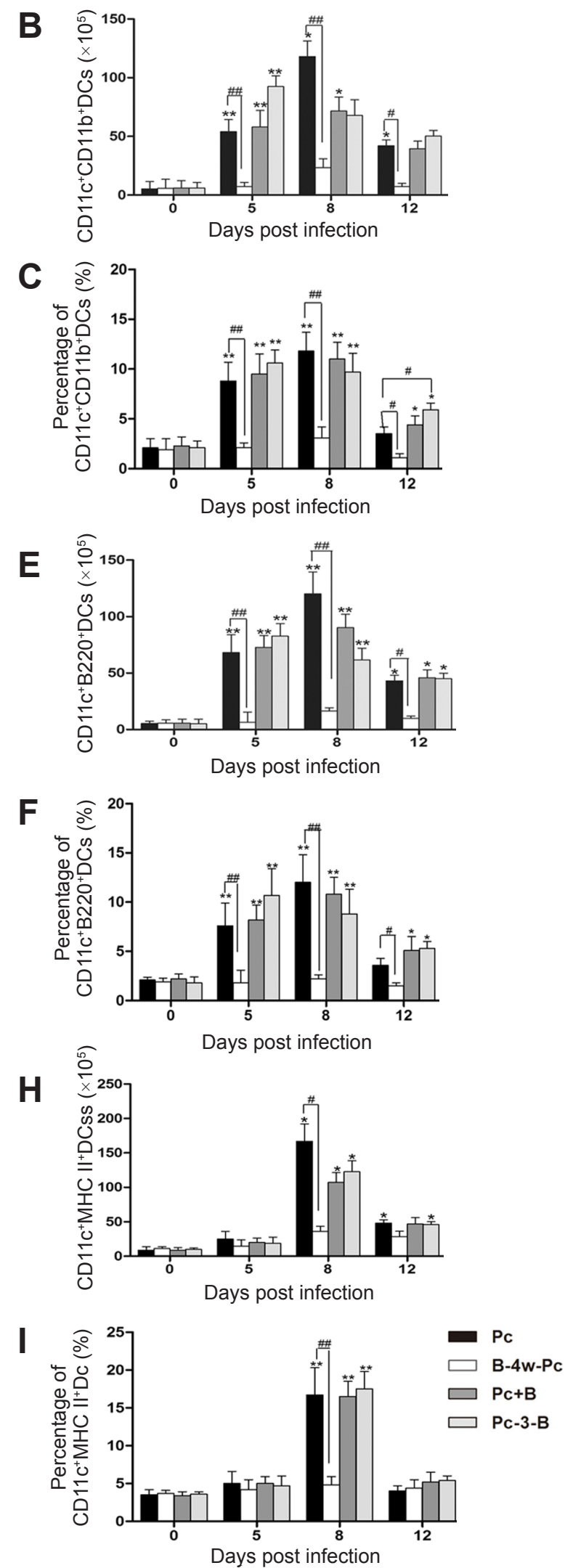

Fig. 4. The effect of BCG-inoculation on DCs of C57BL/6 mice during infection with Plasmodium chabaudi chabaudi Landau, 1965 AS. On 0 (non-infection), 5, 8 and 12 days post infection flow cytometry was used to quantify mDC, pDC, and MHC II surface expression on splenic CD11 $\mathrm{c}^{+}$DCs. Illustration of the gating strategy used to identify splenic $\mathrm{CD} 11 \mathrm{c}^{+} \mathrm{CD} 11 \mathrm{~b}^{+} \mathrm{DCs}, \mathrm{CD} 11 \mathrm{c}^{+} \mathrm{B} 220^{+} \mathrm{DCs}$, and $\mathrm{CD} 11 \mathrm{c}^{+} \mathrm{MHC} \mathrm{II}^{+} \mathrm{DCs}$ using representative dot plots $(\mathbf{A}, \mathbf{D}, \mathbf{G})$. Absolute number of $\mathrm{CD} 11 \mathrm{c}^{+} \mathrm{CD} 11 \mathrm{~b}^{+} \mathrm{DCs}, \mathrm{CD} 11 \mathrm{c}^{+} \mathrm{B} 220^{+} \mathrm{DCs}$, and $\mathrm{CD} 11 \mathrm{c}^{+} \mathrm{MHC} \mathrm{II}^{+} \mathrm{DCs}$ at various time points post infection $(\mathbf{B}, \mathbf{E}, \mathbf{H})$. Proportion of CD $11 \mathrm{c}^{+} \mathrm{CD} 11 \mathrm{~b}^{+} \mathrm{DCs}, \mathrm{CD} 11 \mathrm{c}^{+} \mathrm{B} 220^{+} \mathrm{DCs}$ and $\mathrm{CD}-$ $11 \mathrm{c}^{+} \mathrm{MHC} \mathrm{II}^{+} \mathrm{DCs}$ at various time points post infection $(\mathbf{C}, \mathbf{F}, \mathbf{I})$. Each experiment was repeated three times. Values represent the mean \pm SEM ( $\mathrm{n}=5$ mice per group). * indicates $P<0.05$ and ** indicates $P<0.01$ between experimental groups and non-infected mice; \# indicates $P<0.05$ and \#\# indicates $P<0.01$ between BCG-innoculated mice and control. 
The effect of BCG-inoculation on Tregs and antiinflammatory cytokines in $\mathrm{C57} \mathrm{BL} / 6$ mice during infection with Plasmodium chabaudi chabaudi AS

To analyse the role of Tregs in the response to BCG-malaria co-infection, we first followed the kinetics of Tregs in different groups of mice. As shown in Fig. 3, the absolute number and proportion of $\mathrm{CD} 4{ }^{+} \mathrm{CD} 25^{+} \mathrm{Foxp} 3^{+}$Tregs in the control group significantly increased on $5(P<0.05)$ and $12 \mathrm{dpi}(P<0.01)$. These values in the $\mathrm{B}-4 \mathrm{w}-\mathrm{Pc}$ group were significantly higher on 5 and 8 dpi $(P<0.05)$, but remarkably lower on $12 \mathrm{dpi}(P<0.01)$ as compared to the control group. No significant difference was detected between control and the $\mathrm{Pc}+\mathrm{B}$ group or Pc-3-B group except on $12 \mathrm{dpi}$ (Fig. 3B,C). We further analysed production of the anti-inflammatory cytokine IL-10 to BCG-malaria co-infection. The production of IL-10 in the B-4w-Pc group was significantly lower on 5 and 8 dpi $(P<0.01)$, but conspicuously higher on $12 \mathrm{dpi}(P<0.01)$ as compared to the control group. There was no significant difference between control and the $\mathrm{Pc}+\mathrm{B}$ group or $\mathrm{Pc}-3-\mathrm{B}$ group in the production of IL-10 (Fig. 3D).

\section{The effect of BCG-inoculation on DCs in C57BL/6 mice during infection with Plasmodium chabaudi chabaudi AS}

To investigate the effects of BCG-inoculation on the regulation of DCs, the absolute number and proportion of mDCs and pDCs were detected by flow cytometry. The proportion of $\mathrm{mDCs}$ and $\mathrm{pDCs}$ on $5,8(P<0.01)$ and 12 dpi $(P<0.05)$ in the B-4w-Pc group was significantly lower than in the control group. There was no significant difference between control and the $\mathrm{Pc}+\mathrm{B}$ group or the Pc3 -B group with except for a significant increase in $\mathrm{mDCs}$ in the Pc-3-B group on 12 dpi $(P<0.05)$ (Fig. 4B,C,E,F). We further compared the expression of the DC maturation marker, MHC II, in splenic CD11 $\mathrm{c}^{+}$DCs. The expression of MHC II on 8 dpi on DCs in the B-4w-Pc group was significantly lower than that on DCs of the control group $(P<0.01)$, but no significant difference was observed between control and the $\mathrm{Pc}+\mathrm{B}$ group or the Pc-3-B group at the indicated time points (Fig. 4H,I).

\section{DISCUSSION}

The ability to control parasite density has long been recognised as crucial to a favourable outcome during malarial infection (Stevenson and Riley 2004). Previous studies have shown that protective immune responses induced by infection with species of Plasmodium can effectively control or eliminate parasites in the host (Taylor-Robinson and Phillips 1994, Couper et al. 2005, Seixas and Ostler 2005, Yazdani et al. 2006). In the present study, the determination of parasitemia from tail blood smears indicated that poor outcome in the B-4w-Pc group was associated with a higher parasite density a day earlier than in the control group. The peak level of parasitemia in the B-4w-Pc group was almost two-fold that of the $\mathrm{Pc}+\mathrm{B}, \mathrm{Pc}-3-\mathrm{B}$ and control groups. Coupled with this finding, all mice in the B-4w-Pc group succumbed to infection with Plasmodium c. chabaudi AS by day 20 pi. It has been argued that the ability to control parasite density is closely linked to survival. Taken together, these results suggest that BCG-malaria co-infection at different time points may modulate the host immune response and result in the differences in the development of protective immunity to $P$. c. chabaudi AS infection. More importantly, BCG inoculation 4 weeks prior to $P$. c. chabaudi AS infection did not delay or reduce parasitaemia (in fact it encouraged earlier appearance and a higher peak), turning what is otherwise a self-curing model of malaria infection into a fatal one.

Successful resistance to blood-stage malarial infection depends on the ability to induce an early effective Th1 immunity for controlling parasite growth, which is characterised by predominant IFN- $\gamma$ secretion and effective NO production (Malhotra et al. 2005, Wang et al. 2009, Bueno et al. 2010). A previous study has shown that TNF is toxic to parasites in vivo (Taverne et al. 1989) and indicates that the kinetics of TNF release is coordinated with the reduction in parasite density (Stevenson et al. 1992). Mycobacterial infection also potentially induces Th1 immune responses characterised by predominant IFN- $\gamma$ and TNF- $\alpha$ secretion, which has been confirmed in experiments with animals and clinical practice (Flynn et al. 1993, Keane et al. 2001). Moreover, BCG-inoculation noticeably elevated the survival rates of $\mathrm{A} / \mathrm{J}$ mice with $P$. yoelli $17 \mathrm{XL}$ infection, and shifted the immune response toward Th1 type. In addition, neutralisation of IFN- $\gamma$ with anti-IFN- $\gamma$ mAb abrogated this protection and mice then developed fulminating infections (Matsumoto et al. 2000).

These findings indicate that potentiation of Th1 immune responses plays a protective role in co-infected mice. However, our present data demonstrate an opposite outcome in C57BL/6 mice inoculated with BCG 4 weeks pre-infection with $P$. c. chabaudi AS. We found that BCG-inoculation in the $\mathrm{Pc}+\mathrm{B}$ and $\mathrm{Pc}-3-\mathrm{B}$ groups did not result in potentiation of Th1 immune responses compared to the control group. More importantly, the levels of IFN- $\gamma$ and TNF- $\alpha$ were significantly reduced and Th1 cells, which mediate pro-inflammatory responses were also remarkably lower in the B-4w-Pc group as compared to the other groups. Leisewitz et al. (2008) have reported that BCG-induced death in P. c. chabaudi AS infected C57BL/6 mice was associated with an excessively increase of $\mathrm{CD}^{+}$expressing IFN- $\gamma$; therefore, their work seems to contradict our findings. Our findings support the view that successful resistance to blood-stage malarial infection depends on the ability to induce an early Th1 immune response in order to control parasite growth.

A group has reported on the influence of pre-infection with Mycobacterium tuberculosis and subsequent co-infection with P. yoelii 17XL in resistant C57BL/6 and susceptible BALB/c mice. This pattern of infection afforded significant protection to $\mathrm{C} 57 \mathrm{BL} / 6$ mice, but there was no protection provided to the $\mathrm{BALB} / \mathrm{c}$ mice. The microarray results suggested a clear trend towards a Th1 response in resistant $\mathrm{C} 57 \mathrm{BL} / 6$ mice in contrast to the susceptible $\mathrm{BALB} / \mathrm{c}$ mice, which was confirmed by cytokine levels in splenocyte culture supernatant (Page et al. 2005). Our previous data have suggested that (i) Treg proliferation is 
causally associated with the suppression of Th1 responses during early malarial infection, leading to elevated parasitemia and mortality in mice (Wu et al. 2007, Feng et al. 2012); (ii) Tregs may have an important role in regulating pro-inflammatory Th1 responses in an IL-10-dependent manner and induce $\mathrm{CD}^{+} \mathrm{T}$ cell apoptosis during early rodent malarial infections (Wu et al. 2007, Chen et al. 2009, Zheng et al. 2009); and (iii) Tregs mediate the incidence and outcome of cerebral malaria (CM) in mice infected with Plasmodium berghei ANKA by modifying the pro-inflammatory response (Wu et al. 2010). In addition, Tregs have a vital role in modulating Th1/Th2 responses and are involved in the shift of Th1 to Th2 cells (Song et al. 2009).

Together, these findings suggest that the disparity of Th immune responses to infection with Plasmodium spp. in mice is controlled by modulation of the host immune-regulatory network, which may play an important role in determining the susceptibility and severity of malaria. In the present study, we found that there was a negative correlation between the dynamic changes of Tregs and the establishment of the pro-inflammatory Th1 response in $\mathrm{C} 57 \mathrm{BL} / 6$ mice when BCG-inoculation occurred four weeks prior to infection with $P$. c. chabaudi AS. The increase in Treg proliferation was not correlated to that of IL10 secretion, which implies that there was no natural and intrinsic relationship between these two biological processes. Our data confirm that an excessive proliferation of Tregs could interfere with the appropriate balance between pro- and anti-inflammatory immune responses, leading to increased parasitemia and mortality in mice.

Dendritive cells (DC) provide a vital bridge between the innate and adaptive immune responses and therefore play an important role in the activation and differentiation of $\mathrm{T}$ cells and in the induction of adaptive immune responses
(Banchereau and Steinman 1998, Diao et al. 2004). The balance between Th1 and Th2 cell development is related to DC maturation and Th1/Th2 cytokine production (Stevenson and Urban 2006, Wykes et al. 2007, Ing and Stevenson 2009). Similarly, the balance between $\mathrm{mDC}$ and pDC subsets renders DCs able to direct the appropriate T-cell response (Liu 2001, Jangpatarapongsa et al. 2008). Up-regulated MHC II and co-stimulatory molecules are characteristic of the DC maturation (Stevenson and Urban 2006, Wykes et al. 2007, Ing and Stevenson 2009). High expression of MHC II is crucial for DCs to present antigens to $\mathrm{CD}^{+}{ }^{+}$Th cells (Roche and Furuta 2015). In contrast with other studies, we found that BCG-inoculation four weeks prior to infection with $P$. c. chabaudi AS dramatically inhibited the activation and maturation of $\mathrm{mDC}$ and $\mathrm{pDC}$ and significantly down-modulated expression of the DC maturation marker, MHC II. Our previous findings suggest Tregs prevent Th1 immune response establishment during early stages of infection with $P$. yoelii $17 \mathrm{XL}$ by inhibiting DC responses (Zheng et al. 2009).

Taken together, BCG-inoculation four weeks prior to infection with $P$. c. chabaudi AS may inhibit the activation and maturation of DCs by inducing the excessive proliferation of Tregs, which is causally associated with the suppression of a moderate Th1 response and therefore contributes to overgrowth of parasites as well as mortality of the mice.

Acknowledgements. Thanks are due to Motomi Torii (Ehime University Graduate School of Medicine, Ehime, Japan) for providing malarial parasite strains of $P$. chabaudi chabaudi AS. This work was supported by grants from NIAID, National Institutes of Health, USA (R01AI099611 and U19AI089672) and the Youth Breeding Project of PLA Medical Science (No. 14QNP004).

\section{REFERENCES}

Artavanis-Tsakonas K., Tongren J.E., Riley E.M. 2003: The war between the malaria parasite and the immune system: immunity, immunoregulation and immunopathology. Clin. Exp. Immunol. 133: 145-152.

Banchereau J., Steinman R.M. 1998: Dendritic cells and the control of immunity. Nature 392: 245-252.

Barclay V.C., Sim D., Chan B.H., Nell L.A., Rabaa M.A., Bell A.S., Anders R.F., Read A.F. 2012: The evolutionary consequences of blood-stage vaccination on the rodent malaria Plasmodium chabaudi. PLoS Biol. 10: e1001368.

Bueno L.L., Morais C.G., Araújo F.F., Gomes J.A., CorrêA-Oliveira R., Soares I.S., Lacerda M.V., Fujiwara R.T., Braga E.M. 2010: Plasmodium vivax: induction of $\mathrm{CD} 4+\mathrm{CD} 25+\mathrm{FoxP} 3+$ regulatory $\mathrm{T}$ cells during infection are directly associated with level of circulating parasites. PLoS ONE 5: e9623.

Cameron A., Reece S.E., Drew D.R., Haydon D.T., Yates A.J. 2013: Plasticity in transmission strategies of the malaria parasite, Plasmodium chabaudi: environmental and genetic effects. Evol. Appl. 6: 365-376.

Chen G., Liu J., Wang Q.H., Wu Y., Feng H., Zheng W., Guo S.Y., Li D.M., Wang J.C., CAO Y.M. 2009: Effects of CD4(+) $\mathrm{CD} 25(+) \mathrm{Foxp} 3(+)$ regulatory $\mathrm{T}$ cells on early Plasmodium yoelii 17XL infection in BALB/c mice. Parasitology 136: 1107-1120.
Clark I.A., Allison A.C., Cox F.E. 1976: Protection of mice against Babesia and Plasmodium with BCG. Nature 259: 309311.

Clark I.A., Virelizier J.L., Carswell E.A., Wood P.R. 1981: Possible importance of macrophage-derived mediators in acute malaria. Infect. Immun. 32: 1058-1066.

Couper K.N., Phillips R.S., Brombacher F., Alexander J. 2005: Parasite-specific IgM plays a significant role in the protective immune response to asexual erythrocytic stage Plasmodium chabaudi AS infection. Parasite Immunol. 27: 171-180.

Cox J., Semoff S., Hommel M. 1987: Plasmodium chabaudi: a rodent malaria model for in vivo and in vitro cytoadherence of malaria parasites in the absence of knobs. Parasite Immunol. 9: 543-561.

Diao J., Winter E., Chen W., Cantin C., Cattral M.S. 2004: Characterization of distinct conventional and plamacytoid dendritic cell-committed precursors in murine bone marrow. J. Immunol. 173: 1826-1833.

Feng H., Zhu X.T., Qi Z.M., Wang Q.H., Wang G.G., PAn Y.Y., Li Y., Zheng L., Jiang Y.J., Shang H., Cui L., CaO Y.M. 2012: Transient attenuated Foxp3 expression on $\mathrm{CD}^{+} \mathrm{T}$ cells treated with 7D4 mAb contributes to the control of parasite burden in DBA/2 mice infected with lethal Plasmodium chabaudi chabaudi AS. Scand. J. Immunol. 75: 46-53. 
Flynn J.L., Chan J., Triebold K.J., Dalton D.K., Stewart T.A., BLoоm B.R. 1993: An essential role for interferon gamma in resistance to Mycobacterium tuberculosis infection. J. Exp. Med. 178: 2249-2254.

Gilks C.F., Walliker D., Newbold C.I. 1990: Relationships between sequestration, antigenic variation and chronic parasitism in Plasmodium chabaudi chabaudi - a rodent malaria model. Parasite Immunol. 12: 45-64.

Haidaris C.G., Haynes J.D., Meltzer M.S., Allison A.C. 1983: Serum containing tumor necrosis factor is cytotoxic for the human malaria parasite Plasmodium falciparum. Infect. Immun. 42: 385-393.

Ing R., Stevenson M.M. 2009: Dendritic cell and NK cell reciprocal cross talk promotes gamma interferon-dependent immunity to blood-stage Plasmodium chabaudi AS infection in mice. Infect. Immun. 77: 770-782.

Jangpatarapongsa K., Сhootong P., Sattabongkot J., Chotivanich K., Sirichaisinthop J., Tungpradabkul S., Hisaeda H., Troye-Blomberg M., Cui L., Udomsangpetch R. 2008: Plasmodium vivax parasites alter the balance of myeloid and plasmacytoid dendritic cells and the induction of regulatory T cells. Eur. J. Immunol. 38: 2697-2705.

Keane J., Gershon S., Wise R.P., Mirabile-Levens E., Kasznica J., Schwieterman W.D., Siegel J.N., Braun M.M. 2001: Tuberculosis associated with infliximab, a tumor necrosis factor alpha-neutralizing agent. N. Engl. J. Med. 345: $1098-1104$.

Langhorne J., Gillard S., Simon B., Slade S., Eichmann K. 1989: Frequencies of CD4+ T cells reactive with Plasmodium chabaudi chabaudi: distinct response kinetics for cells with Th1 and Th2 characteristics during infection. Int. Immunol. 1: $416-424$

Langhorne J., Quin S.J., Sanni L.A. 2002: Mouse models of blood-stage malaria infections: immune responses and cytokines involved in protection and pathology. Chem. Immunol. 80: 204-228.

Leisewitz A.L., Rockett K., Kwiatkowski D. 2008: BCG-malaria co-infection has paradoxical effects on C57BL/6 and A/J mouse strains. Parasite Immunol. 30: 1-12.

LiU Y.J. 2001: Dendritic cell subsets and lineages, and their functions in innate and adaptive immunity. Cell 106: 259-262.

Mackinnon M.J., Walker P.R., Rowe J.A. 2002: Plasmodium chabaudi: rosetting in a rodent malaria model. Exp. Parasitol. 101: 121-128.

Malhotra I., Mungai P., Muchiri E., Ouma J., Sharma S., Kazura J.W., King C.L. 2005: Distinct Th1- and Th2-Type prenatal cytokine responses to Plasmodium falciparum erythrocyte invasion ligands. Infect. Immun. 73: 3462-3470.

Matsumoto S., Yukitake H., Kanbara H., Yamada H., KitAmura A., Yamada T. 2000: Mycobacterium bovis bacillus Calmette-Guérin induces protective immunity against infection by Plasmodium yoelii at blood-stage depending on shifting immunity toward Th1 type and inducing protective IgG2a after the parasite infection. Vaccine 19: 779-787.

Murphy J.R. 1981: Host defenses in murine malaria: nonspecific resistance to Plasmodium berghei generated in response to Mycobacterium bovis infection or Corynebacterium parvum stimulation. Infect. Immun. 33: 199-211.

Page K.R., Jedlicka A.E., Fakheri B., Noland G.S., Kesavan A.K., Scott A.L., Kumar N., Manabe Y.C. 2005: Mycobacterium-induced potentiation of type 1 immune responses and protection against malaria are host specific. Infect. Immun. 73: 8369-8380.

Range N., Magnussen P., Mugomela A., Malenganisho W., Changalucha J., Temu M.M., Mngara J., Krarup H., FriIs H., Andersen A.B. 2007: HIV and parasitic co-infections in tuberculosis patients: a cross-sectional study in Mwanza, Tanzania. Ann. Trop. Med. Parasitol. 101: 343-351.
Roche P.A., Furuta K. 2015: The ins and outs of MHC class II-mediated antigen processing and presentation. Nat. Rev. Immunol. 15: 203-216.

Sam H., Stevenson M.M. 1999: In vivo IL-12 production and IL12 receptors $\beta 1$ and $\beta 2$ mRNA expression in the spleen are differentially up-regulated in resistant B6 and susceptible A/J mice during early blood-stage Plasmodium chabaudi AS malaria. J Immunol. 162: 1582-1589.

Schneider P., Bell A.S., Sim D.G., O’Donnell A.J., Blanford S., Paaijmans K.P., Read A.F., Reece S.E. 2012: Virulence, drug sensitivity and transmission success in the rodent malaria, Plasmodium chabaudi. Proc. Biol. Sci. 279: 4677-4685.

Seixas E., Ostler D. 2005: Plasmodium chabaudi chabaudi (AS): differential cellular responses to infection in resistant and susceptible mice. Exp. Parasitol. 110: 394-405.

Song X., Liang F., Liu N., Luo Y., Xue H., Yuan F., Tan L., Sun Y, XI C., XI Y. 2009: Construction and characterization of a novel DNA vaccine that is potent antigen-specific tolerizing therapy for experimental arthritis by increasing CD4(+)CD25(+) Treg cells and inducing Th1 to Th2 shift in both cells and cytokines. Vaccine 27: 690-700.

Spence P.J., Jarra W., LÉvy P., Nahrendorf W., Langhorne J. 2012: Mosquito transmission of the rodent malaria parasite Plasmodium chabaudi. Malar. J. 11: 407.

Stevenson M., Lemieux S., Skamene E. 1984: Genetic control of resistance to murine malaria. J. Cell. Biochem. 24: 91-102.

Stevenson M.M., Huang D.Y., Podoba J.E., Nowotarski M.E. 1992: Macrophage activation during Plasmodium chabaudi AS infection in resistant $\mathrm{C} 57 \mathrm{BL} / 6$ and susceptible $\mathrm{A} / \mathrm{J}$ mice. Infect. Immun. 60: 1193-1201.

Stevenson M.M., Riley E.M. 2004: Innate immunity to malaria. Nat. Rev. Immunol. 4: 169-180.

Stevenson M.M., Tam M.F. 1993: Differential induction of helper T cell subsets during blood-stage Plasmodium chabaudi AS infection in resistant and susceptible mice. Clin. Exp. Immunol. 92: 77-83.

Stevenson M.M., Tam M.F., Belosevic M., van der Meide P.H., Podoba J.E. 1990: Role of endogenous $\gamma$ interferon in host response to infection with blood-stage Plasmodium chabaudi AS. Infect. Immun. 58: 3225-3232.

Stevenson M.M., Tam M.F., Wolf S.F., Sher A. 1995: IL-12-induced protection against blood-stage Plasmodium chabaudi AS requires IFN- $\gamma$ and TNF- $\alpha$ and occurs via a nitric oxide-dependent mechanism. J. Immunol. 155: 2545-2556.

Stevenson M.M., Urban B.C. 2006: Antigen presentation and dendritic cell biology in malaria. Parasite Immunol. 28: 5-14.

Taverne J., Bate C.A., Playfair J.H. 1989: Induction of TNF in vitro as a model for the identification of toxic malaria antigens. Lymphokine Res. 8: 317-322.

Taverne J., Depledge P., Playfair J.H. 1982: Differential sensitivity in vivo of lethal and nonlethal malarial parasites to endotoxin-induced serum factor. Infect. Immun. 37: 927-934.

Taverne J., Dockrell H.M., Playfair J.H. 1981: Endotoxin-induced serum factor kills malarial parasites in vitro. Infect. Immun. 33: 83-89.

Taylor-Robinson A.W., Phillips R.S. 1994: B cells are required for the switch from Th1 to Th2 regulated immune responses to Plasmodium chabaudi infection. Infect. Immun. 62: 2490-2498.

Taylor-Robinson A.W., Phillips R.S., Severn A., Moncada S., LIEw F.Y. 1993: The role of TH1 and TH2 cells in a rodent malaria infection. Science 260: 1931-1934.

Thapa R., Mallick D., Biswas B. 2010: Perinatal malaria and tuberculosis co-infection: a case report. Int. J. Infect. Dis. 14: e254-6.

Waisberg M., Lin C.K., Huang C.Y., Pena M., Orandle M., Bolland S., Pierce S.K. 2013: The impact of genetic susceptibility to systemic lupus erythematosus on placental malaria in mice. PLoS ONE 8: e62820.

Wang G.G., Chen G., Feng H., Liu J., Jiang Y.J., Shang H., CAO Y.M. 2013: Plasmodium chabaudi AS: distinct CD4(+) 
CD25(+)Foxp3(+) regulatory $\mathrm{T}$ cell responses during infection in DBA/2 and BALB/c mice. Parasitol. Int. 62: 24-31.

Wang Q.H., Liu Y.J., Liu J., Chen G., Zheng W., Wang J.C., CAO Y.M. 2009: Plasmodium yoelii: assessment of production and role of nitric oxide during the early stages of infection in susceptible and resistant mice. Exp. Parasitol. 121: 268-273.

World Health Organization 2014: Global Tuberculosis Report 2014. WHO Press, Geneva, 7 pp.

World Health Organization 2015: World Malaria Report 2015. WHO Press, Geneva, 40 pp.

Wozencraft A.O., Dockrell H.M., Taverne J., Targett G.A., Playfair J.H. 1984: Killing of human malaria parasites by macrophage secretory products. Infect. Immun. 43: 664-669.

Wu J.J., Chen G., Liu J., Wang T., Zheng W., Cao Y.M. 2010: Natural regulatory $\mathrm{T}$ cells mediate the development of cerebral malaria by modifying the pro-inflammatory response. Parasitol. Int. 59: 232-241.
Wu Y., Wang Q.H., Zheng L., Feng H., LiU J., Ma S.H., CaO Y.M. 2007: Plasmodium yoelii: distinct CD4(+)CD25(+) regulatory $\mathrm{T}$ cell responses during the early stages of infection in susceptible and resistant mice. Exp. Parasitol. 115: 301-304.

Wykes M.N., Liu X.Q., Beattie L., Stanisic D.I., Stacey K.J., Sмyтн M.J., Thomas R., Good M.F. 2007: Plasmodium strain determines dendritic cell function essential for survival from malaria. PLoS Pathog. 3: e96.

Yazdani S.S., Mukherjee P., Chauhan V.S., Chitnis C.E. 2006: Immune responses to asexual blood-stages of malaria parasites. Curr. Mol. Med. 6: 187-203.

Zheng W., Wang Q.H., Feng H., Liu J., Meng H.R., Cao Y.M. 2009: CD4+CD25+Foxp3+ regulatory $\mathrm{T}$ cells prevent the development of Th1 immune response by inhibition of DC function during the early stage of Plasmodium yoelii infection in susceptible BALB/c mice. Folia Parasitol. 56: 242-250.

Cite this article as: Cao D.-H., Wang J.-C., Liu J., Du Y.-T., Cui L.-W., Cao Y.-M. 2016: BCG-inoculation at different time points influences the outcome of C57BL/6 mice infected with Plasmodium chabaudi chabaudi AS. Folia Parasitol. 63: 010. 